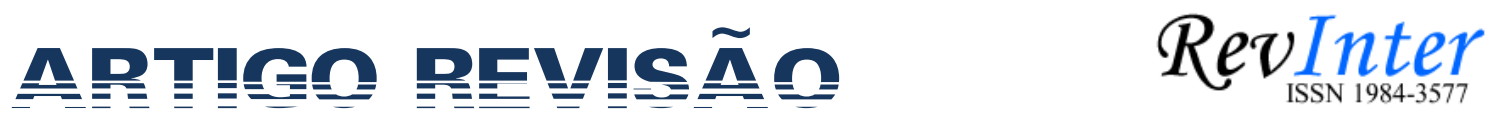

\author{
Utilização na medicina popular, \\ potencial terapêutico e toxicidade em \\ nível celular das plantas Rosmarinus \\ officinalis L., Salvia officinalis L. e \\ Mentha piperita L. (Família Lamiaceae)
}

\section{Geiz Malaquias}

Acadêmica do Curso de Ciências Biológicas. Campus Senador Helvídio Nunes de Barros, Universidade Federal do Piauí. E-mail: geizmalaquias@hotmail.com.

\section{Gilberto Santos Cerqueira}

Docente Adjunto. Departamento de Nutrição. Campus Senador Helvídio Nunes de Barros, Universidade Federal do Piauí. E-mail: giufarmacia@hotmail.com.

\section{Paulo Michel Pinheiro Ferreira}

Docente Adjunto. Departamento de Biofísica e Fisiologia / Programa de Pós-Graduação em Ciências Farmacêuticas (PPGCF), Universidade Federal do Piauí.

*Autor para correspondência: Universidade Federal do Piauí, Avenida Universitária, lado ímpar, Bairro Ininga. Teresina, Piauí. CEP 64.049550. E-mail: pmifepe@yahoo.com.br.

\section{Ana Carolina Landim Pacheco}

Docente Adjunto. Departamento de Ciências Biológicas. Campus Senador Helvídio Nunes de Barros, Universidade Federal do Piauí. Rua Cícero Duarte, n॰ 940. Bairro Junco. Picos, Piauí, Brasil. CEP 64607-670. Email: carolandim@hotmail.com.

\section{João Marcelo de Castro e Souza}

Docente Assistente. Departamento de Ciências Biológicas. Campus Senador Helvídio Nunes de Barros, Universidade Federal do Piauí. Email: j.marcelobiologo@hotmail.com.

MALAQUIAS, Geiz; CERQUEIRA, Gilberto Santos; FERREIRA, Paulo Michel Pinheiro; PACHECO, Ana Carolina Landim; SOUZA, João Marcelo de Castro e; DEUS, Maria do Socorro Meireles de; PERON, Ana Paula. Utilização na medicina popular, potencial terapêutico e toxicidade em nível celular das plantas Rosmarinus officinalis L., Salvia officinalis L. e Mentha piperita L. (Família Lamiaceae). RevInter Revista Intertox de Toxicologia, Risco Ambiental e Sociedade, v. 7, n. 3, p. 50-68, out. 2014. 


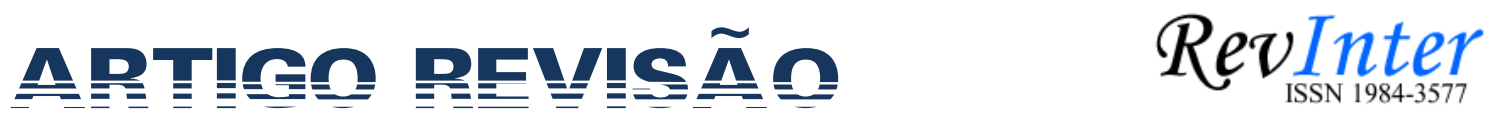

\section{Maria do Socorro Meireles de Deus}

Docente Assistente. Departamento de Ciências Biológicas. Campus Senador Helvídio Nunes de Barros, Universidade Federal do Piauí. Email: socorro_meireles@yahoo.com.br.

\section{Ana Paula Peron*}

\begin{abstract}
Departamento de Ciências Biológicas / Programa de Pós-graduação em Genética e Melhoramento (PPGM). Campus Senador Helvídio Nunes de Barros, Universidade Federal do Piauí. Rua Cícero Duarte, no 940. Bairro Junco. Picos, Piauí, Brasil. CEP 64607-670. E-mail: anpapegenpes@hotmail.com

*Autor para correspondência.
\end{abstract}

\section{RESUMO}

Este trabalho teve por objetivo realizar uma revisão bibliográfica extensa, porém objetiva, sobre a utilização na medicina popular, potencial terapêutico e toxicidade em nível celular das plantas Rosmarinus officinales, Salvia officinales e Mentha piperita, pertencentes a família Lamiaceae, visto que, estas plantas são amplamente cultivadas e utilizadas na medicina popular, e estudadas por pesquisadores do mundo todo quanto aos seus potenciais terapêuticos e toxicológicos. Para realização desta pesquisa consultou-se as bases de dados Scielo, PubMed e Google Acadêmico. Após a análise dos artigos verificou-se que estas plantas, principalmente pela ação dos óleos essenciais, terpenos e flavonóides presentes em suas constituições fitoquímicas, são eficientes, na medicina popular e com ação comprovada cientificamente no tratamento de doenças dos aparelhos digestório, circulatório e respiratório, e do sistema nervoso. Quanto a toxicidade em nível celular destas plantas, as três possuem efeito antiproliferativo, citotóxico, genotóxico e mutagênico a linhagens de células normais e tumorais. A partir desta revisão, reforça-se a importância destas plantas na

MALAQUIAS, Geiz; CERQUEIRA, Gilberto Santos; FERREIRA, Paulo Michel Pinheiro; PACHECO, Ana Carolina Landim; SOUZA, João Marcelo de Castro e; DEUS, Maria do Socorro Meireles de; PERON, Ana Paula. Utilização na medicina popular, potencial terapêutico e toxicidade em nível celular das plantas Rosmarinus officinalis L., Salvia officinalis L. e Mentha piperita L. (Família Lamiaceae). RevInter Revista Intertox de Toxicologia, Risco Ambiental e Sociedade, v. 7, n. 3, p. 50-68, out. 2014. 


\section{n}

cura e amenização de doenças e o potencial para serem usadas, futuramente, como quimiopreventivas.

Palavras-chave: potencial medicinal, ação tóxica as células, alecrim, salvia, hortelã-pimenta.

\section{ABSTRACT}

This study aimed to perform an extensive, but objective, literature review on the use in folk medicine, therapeutic potential and toxicity at the cellular level, of Rosmarinus officinales, Salvia officinales and Mentha piperita belonging to the family Lamiaceae. These plants are widely cultivated and used in folk medicine, and studied by researchers worldwide for its therapeutic and toxicological potential. For this research, the bases of SciELO, PubMed and Google Scholar were consulted. After analyzing the articles it was found that these plants, mainly by the action of its essential oils, terpenes and flavonoids phytochemical in their constitutions are efficient in the treatment of diseases of the digestive apparatus, circulatory and respiratory, and nervous system. As for toxicity at cellular level, the three plants have antiproliferative, cytotoxic, genotoxic and mutagenic effects to strains of normal and tumor cells. From this review, it is reinforced the importance of these plants in healing and alleviation diseases and the potential for being used in the future as a chemopreventive.

Keywords: medicinal potential, action toxic cells, rosemary, salvia e peppermint.

MALAQUIAS, Geiz; CERQUEIRA, Gilberto Santos; FERREIRA, Paulo Michel Pinheiro; PACHECO, Ana Carolina Landim; SOUZA, João Marcelo de Castro e; DEUS, Maria do Socorro Meireles de; PERON, Ana Paula. Utilização na medicina popular, potencial terapêutico e toxicidade em nível celular das plantas Rosmarinus officinalis L., Salvia officinalis L. e Mentha piperita L. (Família Lamiaceae). RevInter Revista Intertox de Toxicologia, Risco Ambiental e Sociedade, v. 7, n. 3, p. 50-68, out. 2014. 


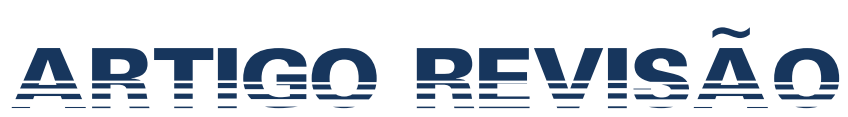

\section{INTRODUÇÃO}

O uso de plantas medicinais tem sido significativo nos últimos tempos. Dados da Organização Mundial de Saúde (OMS) mostram que 80\% da população mundial faz uso da medicina popular para a amenização ou cura de doenças (LOPES et al. 2010). Assim, tem-se verificado um grande avanço científico no entendimento do mecanismo de ação de compostos químicos presentes nas plantas com ações medicinais, bem como seus potenciais tóxicos, como por exemplo, os flavonóides, alcaloides, terpenos, taninos e esteróis, sendo isto claramente observado pelo número de trabalhos científicos publicados nesta área em congressos e em periódicos nacionais e internacionais (CAPELLO et al. 2007).

A família Lamiaceae possui aproximadamente 300 gêneros e 7.500 espécies distribuídas nos diferentes continentes (ALARCON-AGUIAR et al. 2002, AFONSO 2010). Muitas das suas plantas são cultivadas em hortas e jardins, e todas possuem um odor intenso, decorrente da presença de óleos essenciais em suas folhas e flores (SILVA et al. 2010). São também conhecidas por suas propriedades antioxidantes, com destaque as espécies dos gêneros Rosmarinus, Salvia e Mentha, que, em geral, são plantas subarbustivas, de pequeno porte e muito ramificadas (CUVELIER et al. 1994). Em função da composição fitoquímica, estas plantas possuem importante valor econômico, sendo utilizadas na culinária, como condimento, e como ornamentais, na decoração e arejamento de ambientes (VEIGA-JÚNIOR e MELLO 2008).

Outra característica importante é o potencial terapêutico de seus representantes, onde, diferentemente de outras famílias de plantas, a Lamiaceae possui espécies, que além da utilização na medicina popular, possuem grupos químicos com ação terapêutica e tóxica já comprovados por estudos laboratoriais (SILVA et al. 2010). Dentre os gêneros mais importantes das lamiáceas estão o Rosmarinus, Salvia e Mentha, que

MALAQUIAS, Geiz; CERQUEIRA, Gilberto Santos; FERREIRA, Paulo Michel Pinheiro; PACHECO, Ana Carolina Landim; SOUZA, João Marcelo de Castro e; DEUS, Maria do Socorro Meireles de; PERON, Ana Paula. Utilização na medicina popular, potencial terapêutico e toxicidade em nível celular das plantas Rosmarinus officinalis L., Salvia officinalis L. e Mentha piperita L. (Família Lamiaceae). RevInter Revista Intertox de Toxicologia, Risco Ambiental e Sociedade, v. 7, n. 3, p. 50-68, out. 2014. 


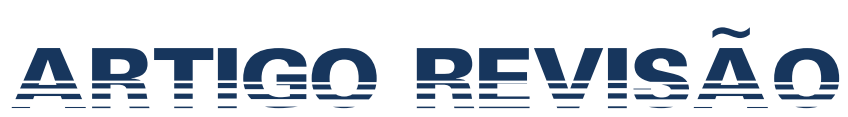

possuem as espécies $R$. officinalis, $S$. officinales e $M$. piperita, respectivamente, como as mais bem definidas em relação a estes aspectos (BAKIKEL et al. 2008).

Nesse contexto, este estudo teve por objetivo abordar, de forma extensa, porém objetiva, a utilização na medicina popular, o potencial terapêutico e a toxicidade em nível celular das plantas $R$. officinalis, $S$. officinales e $M$. piperita.

\section{METODOLOGIA}

Tratou-se de uma pesquisa bibliográfica de base descritiva extensa e objetiva, realizada no período de junho de 2000 a agosto de 2014, por meio de levantamento de dados pesquisados na literatura, utilizando as bases de dados Scielo, PubMed e Google Acadêmico, afim de selecionar estudos, em português e inglês, relevantes para a discussão do tema abordado. Para esta seleção utilizou-se a combinação dos seguintes termos: Lamiaceae, aspectos botânicos, potencial medicinal, toxicidade em nível celular, gênero Rosmarinus, espécie Rosmarinus officinales, alecrim, gênero Salvia, espécie Salvia officinales, Salvia, gênero Mentha, espécie Mentha piperita e hortelãpimenta.

\section{Desenvolvimento}

A utilização de plantas para tratamento, cura e prevenção de enfermidades é uma das mais antigas formas de prática medicinal da humanidade, onde se tem registrados diferentes procedimentos utilizando estes organismos. Apesar da grande evolução da medicina alopática a partir do século XX, ainda existem obstáculos básicos para a utilização dos medicamentos sintéticos por parte da população, em função, muitas vezes, do difícil acesso aos centros de atendimento hospitalares e do valor cobrado por estes medicamentos (COSTA 2008). Estes motivos, associados a fácil

MALAQUIAS, Geiz; CERQUEIRA, Gilberto Santos; FERREIRA, Paulo Michel Pinheiro; PACHECO, Ana Carolina Landim; SOUZA, João Marcelo de Castro e; DEUS, Maria do Socorro Meireles de; PERON, Ana Paula. Utilização na medicina popular, potencial terapêutico e toxicidade em nível celular das plantas Rosmarinus officinalis L., Salvia officinalis L. e Mentha piperita L. (Família Lamiaceae). RevInter Revista Intertox de Toxicologia, Risco Ambiental e Sociedade, v. 7, n. 3, p. 50-68, out. 2014. 


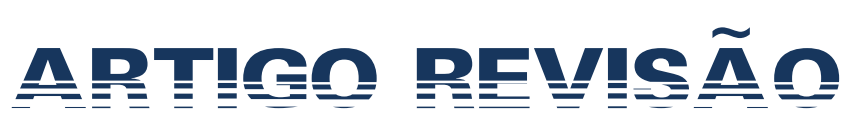

obtenção e a grande tradição no uso de plantas medicinais, contribuem para a utilização destas plantas na medicina popular, principalmente pelas populações dos países em desenvolvimento (CALIXTO 2005, VEIGAJÚNIOR e MELLO 2008).

Dentre as plantas amplamente utilizadas como medicamento no mundo todo estão as da família Lamiaceae, pertencentes à subclasse Asteridae e a ordem Lamiales, com 300 gêneros e 7.500 espécies encontradas nos mais variados habitats (MAYER 2009). Seus representantes são típicos de savana, mas podem ser encontrados em áreas quentes de todo o mundo. No Brasil, esta família, até o momento, é representada por 34 gêneros, dos quais quatro são endêmicos, e por 498 espécies, das quais 334 são endêmicas (HARLEY et al. 2013).

Seus representantes possuem caule curto e lenhoso, e flores pequenas de coloração azul a violeta dispostas em inflorescências. Usualmente, são cultivados em hortas e jardins residenciais, com destaque as espécies dos gêneros Ocimum, Lavandula, Mentha, Majorana, Rosmarinus e Salvia. Possuem odor intenso, e por isso classificadas como aromáticas, decorrentes de suas folhas e flores serem ricamente constituídas por óleos essenciais (BARREIRO 2006). Em função da constituição fitoquímica, muitas destas espécies são utilizadas como condimentos, na decoração de ambientes, na fabricação de cosméticos e, principalmente, para fins medicinais (HARLEY et al. 2013).

\section{Ações medicinais e toxicidade em nível celular da espécie $R$. officinalis}

Dentre os representantes da família Lamiaceae encontra-se a $R$. officinalis L., conhecida popularmente como alecrim. Esta espécie possui origem na região mediterrânea da Europa, mas é cultivada em quase todos os países de clima tropical, como por exemplo, o Brasil, e encontrada em

MALAQUIAS, Geiz; CERQUEIRA, Gilberto Santos; FERREIRA, Paulo Michel Pinheiro; PACHECO, Ana Carolina Landim; SOUZA, João Marcelo de Castro e; DEUS, Maria do Socorro Meireles de; PERON, Ana Paula. Utilização na medicina popular, potencial terapêutico e toxicidade em nível celular das plantas Rosmarinus officinalis L., Salvia officinalis L. e Mentha piperita L. (Família Lamiaceae). RevInter Revista Intertox de Toxicologia, Risco Ambiental e Sociedade, v. 7, n. 3, p. 50-68, out. 2014. 


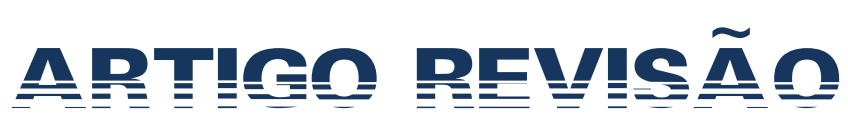

quintais residenciais; ervanários, na forma in natura e seca moída; e hortas. Além de alecrim, esta herbácea também é conhecida por alecrim-de-cheiro, alecrim-das-hortas, alecrim-da-casa, alecrim-comum, alecrim verdadeiro e rosmaninho (SILVA et al. 2010).

Em relação a constituição botânica, o alecrim possui porte subarbustivo lenhoso, ereto de até $1,5 \mathrm{~m}$ de altura, pouco ramificado com folhas pequenas, lineares, coriáceas, de aroma forte, de $1,5 \mathrm{a} 4 \mathrm{~cm}$ de comprimento por 1 a $3 \mathrm{~mm}$ de espessura, flores pequenas de cor azul-claro e de aroma intenso (ANGIONI et al. 2004). Na constituição fitoquímica de suas folhas e flores ocorrem a presença de diterpenos, como o ácido carnósico (presente de forma marjoritária), carnosol, rosmadiol, rosmanol, epirosmanol, rosmaquinonas e metil carnosato. Também são encontrados os flavonóides, como a genkvanina, cirsmaritina, diosmetina, diosmina, gencuanina, luteolina, hispidulina e apigenina; os ácidos caféico, clorogênico e rosmarínico; e esteróis (SILVA et al. 2010).

$\mathrm{Na}$ medicina popular dos países da América do Sul e da Europa as folhas e flores do alecrim são utilizadas em infusão para a amenização de flatulência epigástricas, como aceladoras da digestão, como diurética e digestiva, como coleréticas, colagogas, na desobstrução nasal, na eliminação de catarros, como cicatrizantes, antimicrobianas, na amenização de problemas circulatórios e reumáticos (LORENZI e MATOS 2002, AFONSO et al. 2010), na amenização de dores de cabeça, enxaquecas, tonturas, falta de memória, depressão, na cura de eczemas, como analgésicos para dores de garganta (SILVA et al. 2010), na amenização de mialgias, neuralgias intercostal e dor ciática, na amenização de cansaço físico e mental (HEINRICH et al. 2006), e como antidiabético (BAKIKEL et al. 2008).

No entanto, nas últimas décadas, ocorreram mudanças importantes no conceito de medicamentos de origem vegetal, onde as indústrias farmacêuticas e outros laboratórios de pesquisas passaram a considerar

MALAQUIAS, Geiz; CERQUEIRA, Gilberto Santos; FERREIRA, Paulo Michel Pinheiro; PACHECO, Ana Carolina Landim; SOUZA, João Marcelo de Castro e; DEUS, Maria do Socorro Meireles de; PERON, Ana Paula. Utilização na medicina popular, potencial terapêutico e toxicidade em nível celular das plantas Rosmarinus officinalis L., Salvia officinalis L. e Mentha piperita L. (Família Lamiaceae). RevInter Revista Intertox de Toxicologia, Risco Ambiental e Sociedade, v. 7, n. 3, p. 50-68, out. 2014. 


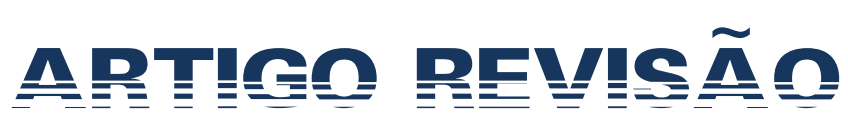

plantas medicinais, como a $R$. officinales e outros representantes da família Lamiaceae, importantes protótipos para o desenvolvimento de novos medicamentos. Atualmente, laboratórios em todo mundo estudam a ação medicinal dos compostos químicos presentes nesta espécie. A seguir, serão citados estudos realizados com compostos químicos presentes na constituição fitoquímica nas folhas e flores do alecrim.

Heinrich e colaboradores (2006) e Hussain e colaboradores (2010) verificaram atividade antioxidante e antitumoral, respectivamente, em roedores tratados com os terpenos rosmadiol e rosmanol extraídos das folhas do alecrim. Ainda, estudos laboratoriais demonstraram que o ácido carnósico isolado desta planta protege os cloroplastos da oxidação, retirando radicais livres, durante situações de estresse na planta, como baixa umidade e altas temperaturas. Pesquisas realizadas com roedores mostraram que o efeito antioxidante dos seus terpenos carnosol foi superior aos do antioxidante sintético butil-hidróxi-anisol (BHA) e semelhante a do antioxidante sintético butil-hidróxi-tolueno (BHT). Também se verificou que o seu diterpeno carnosol possui a habilidade de reduzir danos oxidativos causados ao DNA, a proteínas e as membranas fosfolipídicas de mamíferos.

Hussain e colaboradores (2010) relataram, a partir de estudos realizados com animais e culturas de células, que os terpenos encontrados no alecrim desempenham importante papel na regulação da atividade e/ou expressão de sistemas enzimáticos implicados em processos fisiológicos vitais ao organismo, como apoptose, destruição de células tumorais, transdução do sinal intracelular e regulação de enzimas que metabolizam xenobióticos no fígado, como a superóxido dismutase, catalase e glutationa transferase. Estes autores também relatam que a natureza lipofílica dos terpenos extraído do alecrim tem nas membranas biológicas um dos principais alvos para a sua atividade, visto que, o ácido carnósico e seus

MALAQUIAS, Geiz; CERQUEIRA, Gilberto Santos; FERREIRA, Paulo Michel Pinheiro; PACHECO, Ana Carolina Landim; SOUZA, João Marcelo de Castro e; DEUS, Maria do Socorro Meireles de; PERON, Ana Paula. Utilização na medicina popular, potencial terapêutico e toxicidade em nível celular das plantas Rosmarinus officinalis L., Salvia officinalis L. e Mentha piperita L. (Família Lamiaceae). RevInter Revista Intertox de Toxicologia, Risco Ambiental e Sociedade, v. 7, n. 3, p. 50-68, out. 2014. 


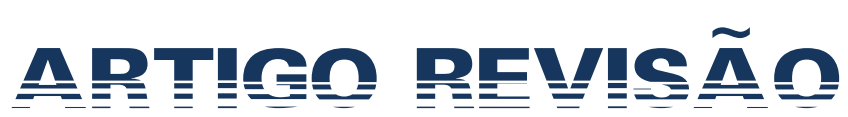

derivados foram encontrados associados a membranas de cloroplastos, protegendo estas estruturas.

Trabalhos mostraram a eficácia do óleo essencial de $R$. officinales em aumentar o desenvolvimento cognitivo em seres humanos saudáveis submetidos a uma bateria de testes computadorizados, onde foi observado que o impacto olfatório causado por este óleo realça significativamente a qualidade total da memória secundária. Dentre as ações farmacológicas desta espécie comprovadas cientificamente tem-se observado também a ação hipoglicemiante, a atividade inibidora da enzima acetilcolinesterase e da $a$ amilase, e efeito hepatoprotetor contra agentes hepatotóxicos, como aos compostos tetracloreto de carbono ( $\mathrm{CCl} 4)$, tetra-butilhidroperóxido (t-BHP), ciclofosfamida e azatioprina (YESIL-CELIKTAS et al. 2010)

Ainda, Visanji e colaboradores (2006) relataram a ação antimicrobiana do extrato etanólico de alecrim frente a bactérias sensíveis e resistentes a antibióticos sintéticos, onde foi possível verificar sinergismo entre antibióticos e os extratos desta planta, possibilitando que antibióticos ineficazes apresentassem ação sobre bactérias resistentes. Estes autores ainda demonstraram demostraram atividade bacteriostática e fungiostática do extrato aquoso de alecrim por meio da técnica do orifício em ágar.

Em relação a toxicidade em nível celular desta planta, pode-se citar sua atividade celular antiproliferativa. Esta atividade é atribuída à ação dos compostos químicos rosmarinidifenol, rosmariquinona e rosmanol (YESIL-CELIKTAS et al. 2010). Segundo Visanji e colaboradores (2006), altas concentrações destes terpenos estacionam o ciclo celular na fase G2 da interfase por interromper a duplicação do citoplasma e o início da condensação cromossômica. Estes autores ainda observaram que superdosagens do diterpeno carnosol tem a ação de estacionar células em divisão, no estágio de prometáfase, por atuar sobre as ciclinas B1 durante a divisão celular, não permitindo a formação adequada do fuso mitótico. Este dado

MALAQUIAS, Geiz; CERQUEIRA, Gilberto Santos; FERREIRA, Paulo Michel Pinheiro; PACHECO, Ana Carolina Landim; SOUZA, João Marcelo de Castro e; DEUS, Maria do Socorro Meireles de; PERON, Ana Paula. Utilização na medicina popular, potencial terapêutico e toxicidade em nível celular das plantas Rosmarinus officinalis L., Salvia officinalis L. e Mentha piperita L. (Família Lamiaceae). RevInter Revista Intertox de Toxicologia, Risco Ambiental e Sociedade, v. 7, n. 3, p. 50-68, out. 2014. 


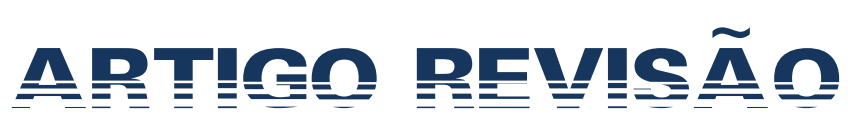

corrobora aos resultados obtidos neste trabalho, onde em todos os TR, nos três TE, ocorreu um grande número de células em prófase (Tabela 1).

Muitas pesquisas sobre o efeito antiproliferativo do alecrim foram realizadas nos últimos anos, como a de Yesil-Celiktas e colaboradores (2010) que avaliaram a ação de extratos aquosos e alcóolicos das folhas de $R$. officinalis, em concentrações consideradas elevadas, que variaram de 12,50 a 47,55 microg/mL, sobre as linhagens de células humanas NCI-H82 (células de carcinoma de pulmão), DU-145 (células de carcinoma de próstata), Hep3B (células de carcinoma de fígado), K-562 (leucemia mielóide crônica) e MCF-7 (adenocarcinoma da mama) e verificaram que o alecrim inibiu significativamente a divisão celular em todas elas.

De modo semelhante, Tai e colaboradores (2012) e Cheng e colaboradores (2011) observaram redução significativa do índice mitótico em células da linhagem A2780 (células cancerosas de ovário humano), e de várias linhagens celulares de carcinomas de cólon de roedores tratadas com concentrações elevadas de carnosol, respectivamente. Dessa forma, a planta alecrim tem sido considerada por muitos pesquisadores como um potente anticancerígeno, antitumoral e quimiopreventivo.

\section{Ações medicinais e toxicidade em nível celular da espécie $S$. officinalis}

Outra espécie da família Lamiaceae, porém do gênero Salvia, muito utilizada na medicina popular de todo o mundo e que, recentemente, tem sido amplamente estudada quanto ao seu potencial medicinal por pesquisadores de muitos países, é a $S$. officinales L., conhecida popularmente como salva, salva-das-boticas e salva-dos-jardins. É uma planta originária do Mediterrâneo, e, da mesma forma que o alecrim, é encontrada no mundo todo (PIEROZAN et al. 2009). Suas plantas apresentam hábito de crescimento herbáceo ou arbustivo muito ramificado,

MALAQUIAS, Geiz; CERQUEIRA, Gilberto Santos; FERREIRA, Paulo Michel Pinheiro; PACHECO, Ana Carolina Landim; SOUZA, João Marcelo de Castro e; DEUS, Maria do Socorro Meireles de; PERON, Ana Paula. Utilização na medicina popular, potencial terapêutico e toxicidade em nível celular das plantas Rosmarinus officinalis L., Salvia officinalis L. e Mentha piperita L. (Família Lamiaceae). RevInter Revista Intertox de Toxicologia, Risco Ambiental e Sociedade, v. 7, n. 3, p. 50-68, out. 2014. 


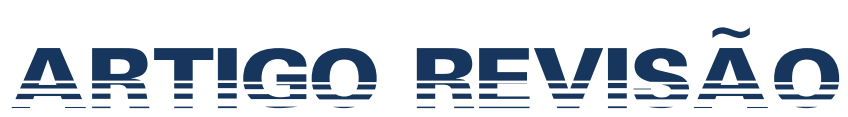

de pequeno porte, medindo entre 50 a $80 \mathrm{~cm}$, com florescimento entre os meses de agosto e dezembro (LORENZI e MATOS 2002). Possuem folhas verde-acinzentadas, oval-lanceoladas e largas, e flores agrupadas em espiga (CORRÊA et al. 2003).

$\mathrm{Na}$ composição fitoquímica das flores e folhas desta espécie estão presentes os terpenos ácido carnosólico, ácido oleanólico, ácido ursólico e carnosol; os flavonóides diosmina, luteolina, apigenina e quercetina; o fenol ácido cafeico; os óleos essenciais cineol, cânfora, borneol, tuiona; e taninos (LORENZI e MATOS 2002). Na medicina popular a Salvia em infusão é utilizada para amenização da ansiedade, irritabilidade, para dispepsia, na cura de problemas hepáticos e digestivos (PIEROZAN et al. 2009), como redutora da lactação, antiglicemiante, antimicrobiana, na higiene bucal, no combate a leucorréias, na cicatrização de feridas (ALONSO 2004, LIMA et al. 2005), na cura de aftas, no combate a dores de dente, na cura de úlceras e como emenagoga (LORENZI e MATOS 2002).

Estudos laboratoriais demonstraram que os terpenos presentes na composição fitoquímica das folhas e flores da $S$. officinales possui grande potencial antiinflamatório, antiproliferativo e neuroprotetor as células de roedores e humanos (POECKEL et al., 2008). Em 2007, Bozin e colaboradores avaliaram a capacidade antimicrobiana do cineol e cânfora presentes nesta planta e verificaram que estes compostos químicos agiram contra cepas de Escherichia coli L., Salmonella typhi L., Salmonella enteritidis L. e Shigella sonei L.

Poeckel e colaboradores (2008) demonstraram a capacidade dos terpenos ácido carnósico e carnosol extraídos da Salvia agirem em células de roedores diretamente em agentes pró-inflamatórios, inibindo células polimorfonucleares (PLM) e a formação de leucotrienos. Maryam e colaboradores (2005) demonstraram o efeito hipoglicemiante do extrato metanólico de folhas de $S$. officinalis em ratos diabéticos induzidos por

MALAQUIAS, Geiz; CERQUEIRA, Gilberto Santos; FERREIRA, Paulo Michel Pinheiro; PACHECO, Ana Carolina Landim; SOUZA, João Marcelo de Castro e; DEUS, Maria do Socorro Meireles de; PERON, Ana Paula. Utilização na medicina popular, potencial terapêutico e toxicidade em nível celular das plantas Rosmarinus officinalis L., Salvia officinalis L. e Mentha piperita L. (Família Lamiaceae). RevInter Revista Intertox de Toxicologia, Risco Ambiental e Sociedade, v. 7, n. 3, p. 50-68, out. 2014. 


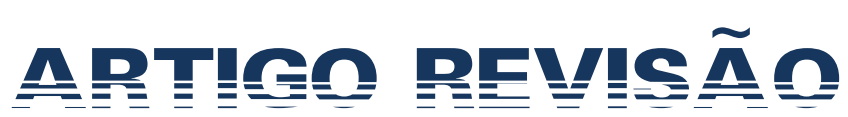

estreptozotocina. Ainda, Rodrigues e colaboradores (2003) observaram potencial cicatrizante do ácido oleanólico em ratos com úlceras induzidas por ácido acético.

Em relação a toxicidade em nível celular utilizando extratos de Salvia, estudos como os de Nicollela e colaboradores (2014) mostraram que o extrato aquoso das folhas desta planta promoveu o aparecimento de micronúcleos em cultura de células de fibroblastos de pulmão de hamster chinês (V79) e em cultura de células de hepatoma humano. Também reduziu de forma significativa o índice de divisão celular destas células, mostrandose citotóxico e mutagênico as linhagens de células em questão.

Sertel e colaboradores (2011) observaram que altas concentrações do óleo essencial de $S$. officinalis foram citotóxicas e mutagênicas a linhagem HNSCC, linhagem de carcinoma da cavidade oral de humanos, reduzindo a viabilidade celular ao mínimo. Loizzo e colaboradores (2007) verificaram que o óleo essencial extraído das folhas e flores de desta planta tem grande potencial em inibir a divisão celular em células de tumor humano, como nos casos de câncer renal, de próstata, de mama e de pele. Da mesma forma que o alecrim, a Salvia tem sido considerada um importante quimiopreventivo. No entanto mais pesquisas devem ser realizadas em diferentes sistemas testes para se afirmar com propriedade esta ação.

\section{Ações medicinais e toxicidade em nível celular da espécie $M$. piperita}

Também pertencentes à família Lameaceae as espécies do gênero Mentha, conhecidas popularmente como hortelãs ou mentas, são muito utilizadas na medicina popular de vários países (DORMAN et al. 2003). Supõe-se que as hortelãs tenham sido introduzidas na Europa, via norte da África (RUSSOMANNO et al. 2005). Atualmente as espécies do gênero

MALAQUIAS, Geiz; CERQUEIRA, Gilberto Santos; FERREIRA, Paulo Michel Pinheiro; PACHECO, Ana Carolina Landim; SOUZA, João Marcelo de Castro e; DEUS, Maria do Socorro Meireles de; PERON, Ana Paula. Utilização na medicina popular, potencial terapêutico e toxicidade em nível celular das plantas Rosmarinus officinalis L., Salvia officinalis L. e Mentha piperita L. (Família Lamiaceae). RevInter Revista Intertox de Toxicologia, Risco Ambiental e Sociedade, v. 7, n. 3, p. 50-68, out. 2014. 


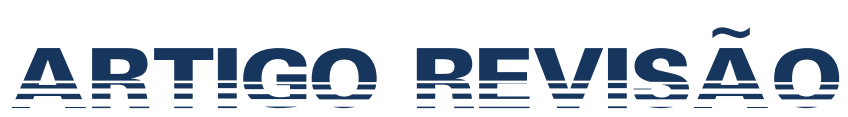

Mentha encontram-se em toda a Europa, África e Américas (PATON et al. $2000 ;$ ).

A mais conhecida popularmente das hortelãs é a espécie $M$. piperita, conhecida popularmente como menta, hortelã e hortelã-pimenta. Trata-se de uma espécie herbácea, perene, de caule subarbustivo com 60 a 90cm de altura, muito ramificados. Possuem folhas pilosas, pecioladas, opostas, lanceoladas e agudas, com bordas serreadas de cor verde escura na face superior e verde clara na face inferior, e com flores, de cor lilás, em espigas terminais (RUSSOMANNO et al. 2005).

Esta espécie, da mesma forma que outras plantas da família Lamiaceae, é rica em óleo essencial que produz um aroma mentolado, balsâmico e fresco, característico do hortelã-pimenta e com diversas aplicações na indústria de alimentos, cosmética e farmacêutica (SILVA 2001). A composição fitoquímica destas plantas são o mentol, mentona, mentofurano, acetato de mentila e pulegona (AFLATUNI 2005; CAPELLO et al. 2005).

De acordo com Cassol (2007) a $M$. piperita é utilizada na medicina popular para a amenização da atonia digestiva, gastralgia, cólicas, afecções hepáticas, bronquite crônica, como calmante, revitalizante, antidepressivo, antialérgico, carminativo, hipotensor, tônico em geral, antiespasmódico, espasmolítica, antiemética, estomáquica e como broncodilatadora (LORENZI e MATOS 2006) e estimulante do sistema nervoso (MIMICA et al. 2003).

Ainda na medicina popular, segundo Lorenzi e Matos (2006), o hortelã-pimenta pode ser utilizado como digestivo, no combate a náuseas e a flatulência, como antivomitivo, na amenização de inflamações de gengiva e cólicas intestinais. O hortelã-pimenta há vários anos é avaliado em estudos laboratoriais quanto ao seu potencial medicinal. Mimica et al. (2003), verificaram que o óleo extraído das folhas desta planta possui propriedade,

MALAQUIAS, Geiz; CERQUEIRA, Gilberto Santos; FERREIRA, Paulo Michel Pinheiro; PACHECO, Ana Carolina Landim; SOUZA, João Marcelo de Castro e; DEUS, Maria do Socorro Meireles de; PERON, Ana Paula. Utilização na medicina popular, potencial terapêutico e toxicidade em nível celular das plantas Rosmarinus officinalis L., Salvia officinalis L. e Mentha piperita L. (Família Lamiaceae). RevInter Revista Intertox de Toxicologia, Risco Ambiental e Sociedade, v. 7, n. 3, p. 50-68, out. 2014. 


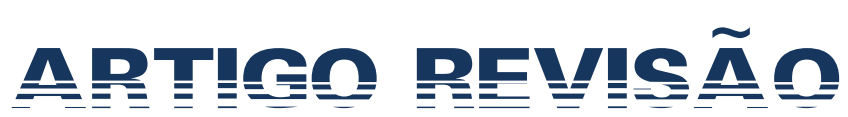

antifúgica; antibactericida, frente a cepas $E$. coli; e grande potencial antioxidante em células de ratos Wistar, diminuindo drasticamente a concentração de radicais hidroxila $-(\mathrm{OH})$.

Em outro trabalho, Lorenzi e Matos (2006) usaram o óleo de hortelãpimenta no tratamento de transtornos digestivos, melhorando os sintomas abdominais em pacientes com síndrome do cólon irritável. Ainda, testaram o óleo essencial de $M$. piperita em inalação e observaram sua eficiência no tratamento de distúrbios respiratórios. Ainda, verificaram que o óleo desta planta é um potente estimulante do Sistema Nervoso Central em mamíferos, por potencializar o estado de alerta quando inalado. Mimica et al. (2003) relataram que o óleo deste tipo de hortelã possui potente atividade analgésica em humanos, reduzindo de forma significativa a sensibilidade na dor de cabeça e enxaqueca quando administrados em seres humanos. Também verificaram que este óleo é eficiente no combate a acnes e dermatites. Estes autores também citam que o óleo extraído das folhas do hortelã-pimenta é estimulante da circulação especialmente nos casos de lipodistrofia ginóide e varizes.

Smartha e colaboradores (2006) verificaram que extratos aquosos administrado a camundongos Swiss tiveram ação antigenotóxica e quimiopreventivas as células destes animais. Romero-Jimenez (2005) avaliaram o potencial genotóxico de extratos aquosos de $M$. piperita em teste de SMART e verificaram sua capacidade em retirar radicais livres. Assim estes autores afirmam que o as folhas do hortelã-pimenta possuem potente atividade antioxidante.

Ainda, em estudos realizados por Jain e colaboradores (2011) e Ferreira e colaboradores (2014) foi verificado que os óleos essenciais presentes nas folhas desta planta promovem fragmentação das mitocôndria e condensação da cromatina sem perda da integridade da membrana plasmática, acelerando o processo de apoptoses em células de roedores. No entanto,

MALAQUIAS, Geiz; CERQUEIRA, Gilberto Santos; FERREIRA, Paulo Michel Pinheiro; PACHECO, Ana Carolina Landim; SOUZA, João Marcelo de Castro e; DEUS, Maria do Socorro Meireles de; PERON, Ana Paula. Utilização na medicina popular, potencial terapêutico e toxicidade em nível celular das plantas Rosmarinus officinalis L., Salvia officinalis L. e Mentha piperita L. (Família Lamiaceae). RevInter Revista Intertox de Toxicologia, Risco Ambiental e Sociedade, v. 7, n. 3, p. 50-68, out. 2014. 


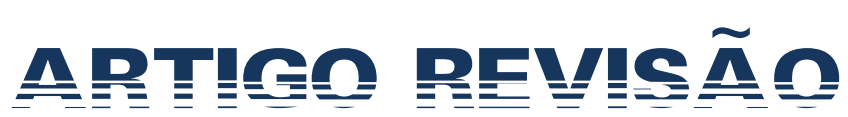

diferentemente do alecrim e da salvia, o hortelã-pimenta ainda foi pouco estudado quanto seu potencial quimiopreventivo. Assim, pesquisadores como Smartha e colaboradores (2006) e Jain e colaboradores (2011) afirmam que mais pesquisas são necessárias para se pra a verificação deste potencial.

\section{CONCLUSÃO}

A partir desta revisão pode se verificar e reforçar a importância medicinal destas três espécies, onde estas plantas, apesar de serem de gêneros diferentes possuem propriedades terapêutica parecidas, com ênfase a atividade citotóxica, genotóxica, mutagênicas e quimiopreventivas a linhagens de células tumorais, principalmente, pela ação de seus óleos essenciais. Assim, é importante que outras plantas da Família Lamiaceae sejam estudas para a verificação de suas ações medicinais bem como os seus potenciais tóxicos em nível celular e assim gerar benefícios a população de um modo geral.

\section{REFERÊNCIAS BIBLIOGRÁFICAS}

AFLATUNI, A. The yield and essential oil content of mint (Mentha ssp.) in northern ostrobothnia. Dissertação de mestrado da Universidade de Oulu, Oulu, 2005.

AFONSO, M. S.; SANT'ANA, L. S.; MANCINI-FILHO, J. Interação entre antioxidantes naturais e espécies reativas de oxigênio nas doenças cardiovasculares: perspectivas para a contribuição do alecrim (Rosmarinus officinalisL.). Nutrire, v.35, n. 1, p.129-148. 2010.

ALARCON-AGUILAR F. J.; ROMAN-RAMOS R.; FLORES-SAENZ J. L.; AGUIRRE-GARCIA F. Investigation on the hypoglycemic effects of extracts of four Mexican medicinal plants in normal and alloxan-diabetic mice. Phytotheraphy Research, v. 16, n. 4, p. 383-386. 2002.

ALONSO, J. Tratado de Fltofarmacos y Nutracéuticos. Rosário, Corpus Libras, 2004. 200p.

ANGIONI, A.; BARRA, A.; CERETI, E.; BARILE, D.; COÏSSON J. D.; ARLORIO M.; DESSI S.; CORONEO, V.; CABRAS, P. Chemical MALAQUIAS, Geiz; CERQUEIRA, Gilberto Santos; FERREIRA, Paulo Michel Pinheiro; PACHECO, Ana Carolina Landim; SOUZA, João Marcelo de Castro e; DEUS, Maria do Socorro Meireles de; PERON, Ana Paula. Utilização na medicina popular, potencial terapêutico e toxicidade em nível celular das plantas Rosmarinus officinalis L., Salvia officinalis L. e Mentha piperita L. (Família Lamiaceae). RevInter Revista Intertox de Toxicologia, Risco Ambiental e Sociedade, v. 7, n. 3, p. 50-68, out. 2014. 


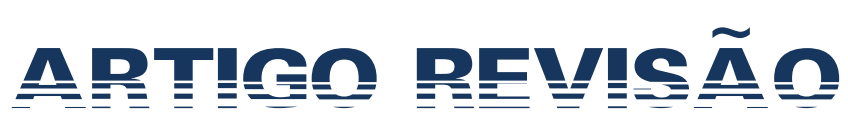

composition, plant genetic differences, antimicrobial and activity investigation of the essential oil Rosmarinus officinalis L._Journal of Agricultural and Food Chemistry, v. 52, p. 1227-1301. 2004.

BAKIREL, T.; BAKIREL, U.; KELES, O. U.; ÜLGEN, S. G.; YARDIBI, H. A avaliação in vivo das atividades antidiabéticos e antioxidantes do alecrim (Rosmarinus officinalis) em coelhos diabéticos aloxano. Jornal de Etnofarmacologia, v. 116, p. 64-73. 2008.

BOZIN, B.; MIMICA-DUKIC, N.; SAMOJLIK, I.; JOVIN, E. Antimicrobial and Antioxidant Properties of Rosemary and Sage (Rosmarinus officinalis L. and Salvia officinalis L., Lamiaceae) Essential Oils. Journal of Agricultural and Food Chemistry, v. 55, p. 7879-7885. 2007.

CALIXTO, J. B. Efficacy, safety, quality control, marketing and regulatory guidelines for herbal medicines (phytotherapeutic agents). Brazilian Journal of Medical and Biological Research, v. 33, n. 2, p. 179-89. 2005.

CAPPELO, G.; SPEZZAFERRO M.; GROSSIL L.; MANZOLI L.; MARZIO L. Peppermint oil (Mintoil) in the treatment of irritable bowel: a prospective double blind placebo controlled randomized trial. Digestive and Liver Disease, v. 39, n. 6, p. 530-536. 2007.

CASSOL, D.; FALQUETO, A. R.; BACARIN, M. A. Fotossíntese em Mentha piperita e Melissa officinalis sob sombreamento. Revista Brasileira de Biociências, v. 5, n. 2, p. 576-578. 2007.

CHENG, AC., LEE, MF., TSAI, ML., LAI, CS., LEE, JH., HO, CT. and PAY, MH., 2011. Rosmanol potently induces apoptosis through both the mitochondrial apoptotic pathway and death receptor pahway in human colon adenocarcinoma COLO 205 cells. Food Chemical Toxicology, vol. 49, n 2, p. 485-493. 2011.

CORRÊEA, A. D.; BATISTA, R. S.; QUINTAS, L. E. M. Plantas medicinais: do cultivo à terapêutica. Petrópolis, Vozes, 2003. 190p.

COSTA, L. C. B. Condições culturais, anatomia foliar, processamento e armazenamento de Ocimum selloi em relação ao óleo essencial. Dissertação de Doutorado em Agronomia, Universidade Federal de Lavras, Lavras - MG, 2008.

MALAQUIAS, Geiz; CERQUEIRA, Gilberto Santos; FERREIRA, Paulo Michel Pinheiro; PACHECO, Ana Carolina Landim; SOUZA, João Marcelo de Castro e; DEUS, Maria do Socorro Meireles de; PERON, Ana Paula. Utilização na medicina popular, potencial terapêutico e toxicidade em nível celular das plantas Rosmarinus officinalis L., Salvia officinalis L. e Mentha piperita L. (Família Lamiaceae). RevInter Revista Intertox de Toxicologia, Risco Ambiental e Sociedade, v. 7, n. 3, p. 50-68, out. 2014. 


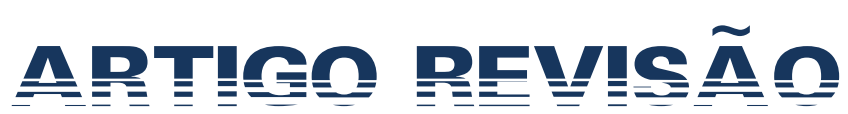

CUVELIER, M. E.; BERSET, C.; RICHARD, H. Antioxidant constituents in sage (Salvia officinalis). Journal of Agricultural Food Chemistry. v. 42, n. 3, p. 665-669. 1994.

DORMAN, H. J. D.; KOSAR, M.; KAHLOS, K.; HOLM, Y.; HILTUNEN, R. Antioxidant properties and composition of aqueous extracts from Mentha species, hybrids, varieties, and cultivars. Journal of Agricultural and Food Chemistry, v. 51, n. 16, p. 4563-4569. 2003.

FERREIRA, P.; CARDOSO, T.; FERREIRA, F.; FERNANDEZ-FERREIRA, M.; PIPER, P.; SOUSA, M. J. Mentha piperitaessential oil induces apoptosis in yeast associated with both cytosolic and mitochondrial ROS-mediated damage. FEMS Yeast Research. 2014. Doi: 10.1111/1567-1364.12189

HARLEY, R.; FRANÇA, F.; SANTOS, E. P.; SANTOS, J. S.; PASTORE, J. F. Lamiaceae. In: Lista de Espécies da Flora do Brasil (2013). Jardim Botânico do Rio de Janeiro Disponível em: $<$ http://reflora.jbrj.gov.br/jabot/floradobrasil/FB8296>. Acesso em: $15 / 07 / 2014$

HEINRICH, M.; KUFER, J.; LEONTI, M.; PARDO-DE-SANTAYANA, M. Ligações interdisciplinares com as ciências históricas - Etnobotânica e etnofarmacologia. Journal of Ethnopharmacology, v. 107, p. 157-160, 2006.

HUSSAIN, A. I.; ANWAR, F.; CHATHA, S. A. S.; JABBAR, A.; MAHBOOB, S.; NIGAM, P. S. Rosmarinus officinalis óleo essencial: antiproliferativo atividades antioxidantes e antibacterianas. Brazilian Journal of Microbiology, v. 41, p. 1070-1078. 2010.

JAIN, D.; PATHAK, N.; KHAN, S.; RAGHURAM, G. V.; BHARGAVA, A.; SAMARTH, R.; MISHRA, P. K. Evaluation of cytotoxicity and anticarcinogenic potential of Mentha leaf extracts. International Journal of Toxicology, v. 30, n. 2, p. 225-236. 2011.

LIMA, C. F., ANDRADE, P. B.; SEABRA R. M.; FERREIRA M. F.; WILSON, P. C. The drinking of a Salvia officinalis infusion improves liver antioxidant status in mice and rats.

LIMA, C. F.; AZEVEDO, M. F.; ARAUJO. R.; FERREIRA M. F.; WILSON, C. P. Metformin-like effect of Salvia officinalis (common sage): is it useful in diabetes prevention? British Journal of Nutrition, v. 2, n. 96, p. 326-333. 2006.

MALAQUIAS, Geiz; CERQUEIRA, Gilberto Santos; FERREIRA, Paulo Michel Pinheiro; PACHECO, Ana Carolina Landim; SOUZA, João Marcelo de Castro e; DEUS, Maria do Socorro Meireles de; PERON, Ana Paula. Utilização na medicina popular, potencial terapêutico e toxicidade em nível celular das plantas Rosmarinus officinalis L., Salvia officinalis L. e Mentha piperita L. (Família Lamiaceae). RevInter Revista Intertox de Toxicologia, Risco Ambiental e Sociedade, v. 7, n. 3, p. 50-68, out. 2014. 


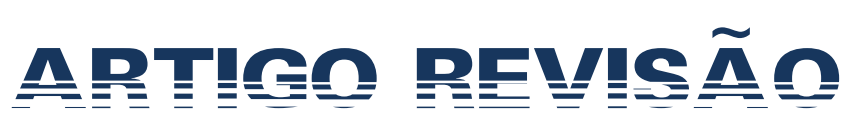

LOIZZO, M. R.. "Cytotoxic activity of essential oils from Labiatae and Lauraceae families against in vitro human tumor models." Anticancer research. v. 27, n.5, p. 3293-3299. 2007.

LOPES R.M., OLIVEIRA T.D., NAGEM T.J., PINTO A.D.S. Flavonóides. Biotecnologia Ciência \& Desenvolvimento. v. 3, n. 14. 2010.

LORENZI, H.; MATOS, F. J. A. Plantas medicinais no Brasil: nativas e exóticas. Nova Odessa, 2002. 300p.

LORENZI, H.; MATOS, F. J. Plantas Medicinais no Brasil: Nativas e Exóticas Cultivadas. Nova Odessa, 2006. 400p.

MAYER, B. Gastroprotective constituents of Salvia officinalis L. Fitoterapia, v. 80, n. 7, p. 421-426. 2009.

MIMICA, D. N.; BOZIN, B.; SOKOVIC, M.; MIHALLOVIC, B.; MATAVULJ, M. Antimicrobial and antioxidante activies af there mente species essential oils. Medicinal plant, v. 69, n. 5, p. 413-9. 2003.

NICOLELLA, H. D. Differential effect of manool, a diterpene from Salvia officinalis on genotoxicity induced by methyl methanesulfonate in V79 and HepG2 cells. Food and Chemical Toxicology (2014).

PATON, A.; HARLEY, R.; HARVEY, T. A newsletter for Lamiaceae \& Verbanaceae research. In: VITEX, Herbarium, Royal Botanic Gardens Kew. 2000. Disponível em: <http://www.rbgkew.org.uk/data/vitex/jan00.pdf> Acesso em: 15/07/2014.

PIEROZAN, M.K. Caracterização química e atividade antimicrobiana de óleos essenciais de Salvia L. espécies. Ciencia e Tecnologia de Alimentos, v.29, n. 4, p. 764-70, 2009.

POECKEL, D.; GREINER, C.; VERHOFF, M.; RAU, O.; TAUSCH, L.; HO"RNIG, C.; STEINHILBER D.; SCHUBERT-ZSILAVECZ, M.; WERZ, O. Carnosic acid and carnosol potently inhibit human 5-lipoxygenase and suppress pro-inflammatory responses of stimulated human polymorphonuclear leukocytes. Biochemical pharmacology. v. 7, n. 6, p. 91-97. 2008.

RUSSOMANNO, O. M. R.; KRUPPA, P. C.; FIGUEIREDO, M. B. Oidium asterispunicei em plantas de hortelã-pimenta. Fitopatologia Brasileira, v. 30, n. 5, p. 551. 2005.

MALAQUIAS, Geiz; CERQUEIRA, Gilberto Santos; FERREIRA, Paulo Michel Pinheiro; PACHECO, Ana Carolina Landim; SOUZA, João Marcelo de Castro e; DEUS, Maria do Socorro Meireles de; PERON, Ana Paula. Utilização na medicina popular, potencial terapêutico e toxicidade em nível celular das plantas Rosmarinus officinalis L., Salvia officinalis L. e Mentha piperita L. (Família Lamiaceae). RevInter Revista Intertox de Toxicologia, Risco Ambiental e Sociedade, v. 7, n. 3, p. 50-68, out. 2014. 


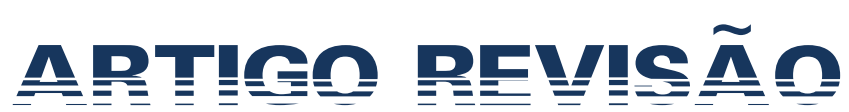

SAMARTH, R. M.; PANWAR, M.; KUMAR, A. Modulatory effectsmof Mentha piperita on lung tumor incidence, genotoxicity and oxidative strees in benzo[a]pyrene-treated Swiss albino mice. Environmental Molecular Mutegenese, v. 47, n.3, p. 192-198. 2006.

SERTEL, S. Anticancer activity of Salvia officinalis essential oil against HNSCC cell line (UMSCC1)]." Hno. v. 59, n.12, p. 1203-1208. 2011.

SILVA, A. B., SILVA, T.; FRANCO, E. S.; RABELO, S. A.; LIMA, E. R.; MOTA, R. A.; CAMARA, C. A. G. da; PONTES-FILHO, N. T. Atividade antibacteriana, composição química, e citotoxicidade do óleo essencial de folhas de árvore de pimenta brasileira (Schinus terebinthifolius Raddi). Brazilian Journal Microbiologic, v. 41, p. 158-163. 2010.

ROMERO-JIMÉNEZ, M.; CAMPUS-SANCHEZ, J.; ANALLA, M.; MUÑOZSERRANO, A.; ALONSO-MORAGA, A. Genotoxicity and anti-genoetoxicity of some tradicional medicinal herbs. Mutation Research, v. 585, n. 1-2, p. 147-155. 2005.

TAI, J.; CHEUNG, S.; WU, M.; HASMAN, D. Antiproliferation effect of Rosemary Rosmarinus officinalis on human ovarian cancer cells in vitro. Phytomedicine,v. 19, n. 05, p. 436-443. 2012.

VISANJI, J.M.; THOMPSON, D.G.; PADFIELD, P.J., 2006. Induction of G2 /M phase cell cycle arrest by carnosol and carnosic acid is associated with alteration of cyclin A and cyclin B1 levels. Cancer letters, v. 237, n. 1, p. 130-136. 2006.

YESIL-CELIKTAS, O.; SEVIMLI, C.; BEDIR, E.; VARDAR-SUKAN, F. Inhibitory effects of rosemary extracts, carnosic acid and rosmarinic acid on the growth of various human cancer cell lines. Plant Foods for Human Nutrition, v. 65, n. 02, p. 158-163. 2010.

MALAQUIAS, Geiz; CERQUEIRA, Gilberto Santos; FERREIRA, Paulo Michel Pinheiro; PACHECO, Ana Carolina Landim; SOUZA, João Marcelo de Castro e; DEUS, Maria do Socorro Meireles de; PERON, Ana Paula. Utilização na medicina popular, potencial terapêutico e toxicidade em nível celular das plantas Rosmarinus officinalis L., Salvia officinalis L. e Mentha piperita L. (Família Lamiaceae). RevInter Revista Intertox de Toxicologia, Risco Ambiental e Sociedade, v. 7, n. 3, p. 50-68, out. 2014. 